\title{
Calidad sanitaria del agua del Parque Natural Chicaque
}

\author{
Sara Lilia Ávila de Navia ${ }^{1}$, Sandra Mónica Estupiñán Torres ${ }^{1}$
}

1. Docentes Universidad Colegio Mayor de Cundinamarca.

Correspondencia: sestupinan@unicolmayor.edu.co

Recibido: 13/02/2013 Aceptado: 28/05/2013

\begin{abstract}
Resumen
La eutrofización es un proceso natural en los ecosistemas acuáticos, se produce por el enriquecimiento del cuerpo de agua con nutrientes. Durante los últimos años el ser humano ha acelerado estos procesos de eutrofización modificando tanto la calidad de las aguas como la estructura de las comunidades biológicas, debido al aumento en la carga orgánica e inorgánica de los cuerpos de agua. La eutrofización reduce los usos potenciales de los recursos hídricos ya que induce a la mortalidad de especies animales, a la descomposición del agua y al crecimiento de microorganismos. Además, en muchas ocasiones los microorganismos se convierten en un riesgo para la salud humana, como es el caso de los agentes patógenos transmitidos por el agua, que constituyen un problema mundial.

Para establecer la calidad microbiológica del agua, se evaluaron once puntos del Parque Natural Chicaque en época de lluvias (noviembre del 2010) y época seca (agosto del 2011). Se emplearon los indicadores coliformes totales, Escherichia coli y Enterococcus, la técnica utilizada fue la filtración por membrana, y la identificación de algunos microorganismos aislados se realizó con pruebas bioquímicas rápidas BD BBL Crystal. El aislamiento de coliformes totales, Escherichia coli y Enterococcus en el agua del Parque, indica la contaminación fecal de las aguas. La presencia de estos grupos de bacterias está relacionada con el impacto de las actividades del hombre y animales sobre los cuerpos de agua y el manejo de las aguas residuales.
\end{abstract}

Palabras clave: calidad microbiológica, coliformes, contaminación del agua, indicadores de contaminación fecal, parques naturales.

\section{Sanitary water quality from Chicaque Natural Park}

\begin{abstract}
Eutrophication is a natural process in aquatic ecosystems; it is produced by the enrichment of the water body with nutrients. In recent years, humans have accelerated the eutrophication process by changing both the water quality and the structure of biological communities due to increased load of organic and inorganic water bodies. Eutrophication reduces the potential uses of water resources and inducing mortality of animal species, the decomposition of water and the growth
\end{abstract}


of microorganisms. In addition, microorganisms often become a risk to human health, such as pathogens transmitted by water, which is a worldwide problem.

To establish the microbiological quality of water, eleven points of the Natural Park Chicaque were evaluated during the rainy season (November 2010) and the dry season (August 2011). The indicators used were total coliforms and Escherichia coli and Enterococcus, the technique used was the membrane filtration, and the identification of some isolated microorganisms was carried out with rapid biochemical tests BBL BD Crystal. The isolation of total coliforms and Escherichia coli and Enterococcus in the water of the Park indicates the fecal contamination of the waters. The presence of these groups of bacteria is related to the impact of the activities of man and animals on the bodies of water and wastewater management

Keywords: coliform bacteria, indicators of fecal pollution, microbiological quality, natural parks, water pollution.

\section{Introducción}

El crecimiento de la población, las industrias, la urbanización, las actividades agropecuarias y el cambio climático son factores que inciden sobre la calidad del agua. El uso inadecuado de este recurso afecta negativamente el equilibrio de los ecosistemas y la salud humana, ya que el agua contaminada es un medio propicio para la transmisión de enfermedades en la población (1).

El agua para consumo humano debe cumplir estándares de calidad, razón por la cual es indispensable evaluar la presencia de microorganismos patógenos como virus, bacterias y parásitos, mediante microorganismos indicadores de contaminación; para evitar así la transmisión de enfermedades como gastroenteritis, diarrea, disentería, hepatitis o fiebre tifoidea, que pueden manifestarse desde cuadros simples hasta cuadros graves (2).

El Parque Natural Chicaque conforma la Micro cuenca alta de la quebrada La Playa (vertiente norte de la cuenca media del río Bogotá), cuyas aguas nacen en la reserva. El área tiene tres quebradas principales (quebrada El Carmen al norte; quebrada La Playa en el centro; y quebrada San Juan al sur). Desde 1990 el parque tiene un uso eco turístico con zona de camping, cabańas, restaurante y un Eco-hotel. Los pastizales mantienen a varias cabezas de ganado bovino y equino en forma extensiva (3). Prácticamente el 100\% del agua usada para consumo humano en el Parque proviene de la quebrada La Playa. Se toma alrededor de los 2.400 msnm y se transporta por mangueras que pueden llegar a tener más de $1 \mathrm{~km}$ hasta los respectivos puntos de consumo (4).

\section{Materiales y métodos}

El Parque Natural Chicaque se encuentra ubicado al suroccidente de la Sabana de Bogotá, en la vertiente occidental de la cordillera oriental y conforma la Microcuenca alta de la quebrada la playa, dentro de la cuenca media del Río Bogotá, entre las coordenadas geográficas $74^{\circ} 18^{\prime} 25.109^{\prime \prime}$ y $74^{\circ} 19^{\prime} 25.187^{\prime \prime}$ de Longitud oeste de Greenwich y $4^{\circ} 36$ '21.215” a 4³7’42.907” de Latitud Norte. Las coordenadas planas de Gauss datum Bogotá para el parque son de 1.000 .761 a $1.003 .271 \mathrm{~m}$ Norte y de 973.064 a $974.915 \mathrm{~m}$ este. El área comprende aproximadamente 308.88 hectáreas, dentro de la vereda de Chicaque, Municipio de San Antonio del Tequendama, colindando con los municipios de Soacha y Bojacá en el Departamento de Cundinamarca (3). 
Para evaluar posibles variaciones temporales de la calidad microbiológica se realizaron dos muestreos, uno en época de lluvias (Noviembre de 2010) y el otro en época seca (Agosto de 2011).

\section{Toma de muestras}

Las muestras de la quebrada se tomaron de acuerdo a lo propuesto por la Organización Mundial de la Salud (OMS), en las Guías para la Calidad del Agua Potable (5). Las muestras de grifos se tomaron de acuerdo a la metodología establecida por la Norma Técnica Colombiana (NTC) 813, contenida en las normas oficiales para la calidad del agua en Colombia (6). Las muestras se reportan en la tabla 1.

Tabla 1. Puntos de muestra, lugar de análisis y coordenadas respectivas

\section{Muestra y sitio de análisis}

1. Nacedero de la parte alta de la portería.

2. Grifo del baño de la portería.

3. Estación de bombeo de la zona alta de camping.

4. Nacedero del afluente de la quebrada La playa.

5. Grifo de la alberca de la zona de camping.

6. Bocatoma de la Quebrada la playa.

7. Grifo de la cocina del refugio.

8. Intersección sendero de la cascada con la Quebrada Chicaque.

9. La cascada

10. Segundo afluente camino a la cascada

11. Quebrada Chicaque parte baja

\section{Coordenada}

N $04^{\circ} 36^{\prime} 16.8^{\prime \prime}$ W $075^{\circ} 18^{\prime} 17.8^{\prime \prime}$

N $04^{\circ} 36^{\prime} 24.0^{\prime \prime}$

W $074^{\circ} 18^{\prime} 18.0 "$

$\mathrm{N} 04^{\circ} 36^{\prime} 29.4^{\prime \prime}$

W $074^{\circ} 18^{\prime} 12.5^{\prime \prime}$

$\mathrm{N} 04^{\circ} 36^{\prime} 29.5^{\prime \prime}$

W $074^{\circ} 18^{\prime} 10.6^{\prime \prime}$

$\mathrm{N} 04^{\circ} 36^{\prime} 29.5^{\prime \prime}$

W $074^{\circ} 18^{\prime} 17.8^{\prime \prime}$

$\mathrm{N} 04^{\circ} 36^{\prime} 48.5^{\prime \prime}$

W $074^{\circ} 18^{\prime} 34.6^{\prime \prime}$

$\mathrm{N} 04^{\circ} 36^{\prime} 53.0^{\prime \prime}$

W $074^{\circ} 18^{\prime} 40.6^{\prime \prime}$

$\mathrm{N} 04^{\circ} 37^{\prime} 10.3$ "

W $074^{\circ} 18^{\prime} 36.1^{\prime \prime}$

N $04^{\circ} 37^{\prime} 25.5^{\prime \prime}$

W $074^{\circ} 18^{\prime} 43.2^{\prime \prime}$

$\mathrm{N} 04^{\circ} 37^{\prime} 12.6 "$

W $074^{\circ} 18^{\prime} 38.9^{\prime \prime}$

N $04^{\circ} 36^{\prime} 56.4^{\prime \prime}$

W $074^{\circ} 18^{\prime} 44.9^{\prime \prime}$

Fuente: las autoras

\section{Procesamiento de las muestras}

La metodología empleada para el análisis de los grupos de microorganismos es la recomendada por la Environmental Protection Agency (EPA) (7); la técnica utilizada para el análisis bacteriológico del agua fue la Filtración por Membrana.
En este método la muestra de agua se hace pasar mediante vacío por un filtro de celulosa de 0.45 micras de tamaño de poro, en donde quedan retenidas las bacterias. El filtro es colocado en un medio de cultivo selectivo para la especie o grupo que se desea determinar en la muestra y se incuba a las condiciones necesarias para cada microorganismo.

Los medios utilizados para la enumeración de las bacterias indicadoras de contaminación de aguas fueron: Bacterias coliformes totales, agar endo NPS.

Escherichia coli, agar M-FC.

Enterococcus, agar azida NPS.

Pseudomonas, agar cetrimide NPS.

Aeromonas, agar m-Aeromonas.

La identificación de algunos de los microorganismos aislados se realizó mediante subcultivos en los mismos medios usados para los recuentos anteriormente mencionados. Después de obtener colonias aisladas, se llevó a cabo la identificación por medio de pruebas bioquímicas rápidas Crystal BBL, para Enterobacterias y bacterias Gram positivas.

\section{Coliformes totales}

\section{Resultados}

En época seca se aprecia un alto número de coliformes totales en la mayoría de las muestras estudiadas, los recuentos UFC/100mL más bajos se presentaron en la muestra 8 y en la muestra $10(\mathrm{Ta}-$ bla 2, Figura 1). En la época de lluvia los recuentos de UFC/100mL más altos se presentaron en la muestra 6 y 11, en los demás puntos los recuentos fueron bajos (Tabla 3, Figura 2). Para la época de lluvias el promedio es de $120 \mathrm{UFC} / 100 \mathrm{~mL}$ considerados inferiores a la época seca donde el promedio es de 980 UFC/100mL de agua (Figura 3).

\section{Escherichia coli}

El recuento para estos microorganismos fue bajo 0-11 UFC/100mL en época seca (Tabla 2, Figura 1). En época de lluvia los recuentos más altos fueron en las muestras 7,10 y 11 (Tabla 3, Figura 2). El promedio para la época de lluvias fue de 7 UFC/100mL superior al recuento promedio de la época seca que fue de 0 UFC/100mL de agua (Figura 3). 
Figura 1. Recuento en Unidades Formadoras de Colonia / $100 \mathrm{~mL}$ durante la época seca

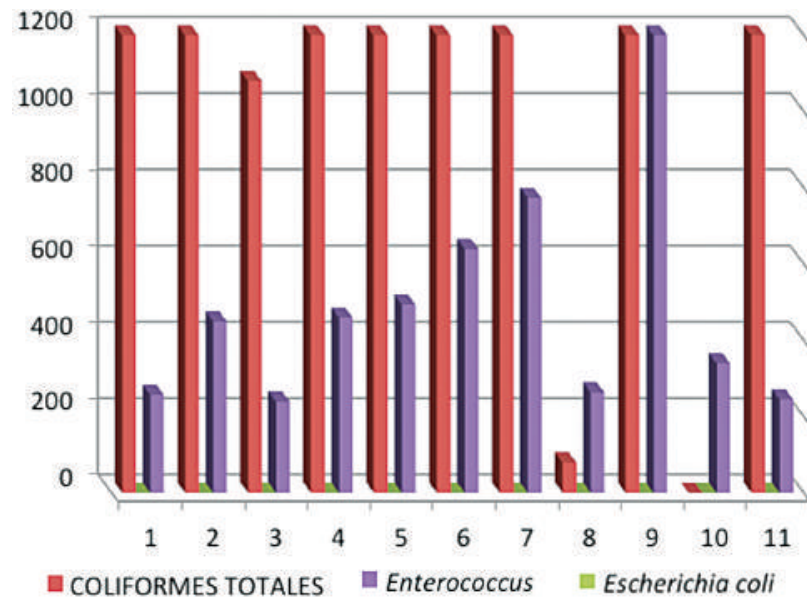

Figura 2. Recuento en Unidades Formadoras de Colonia / $100 \mathrm{~mL}$ durante la época lluvia

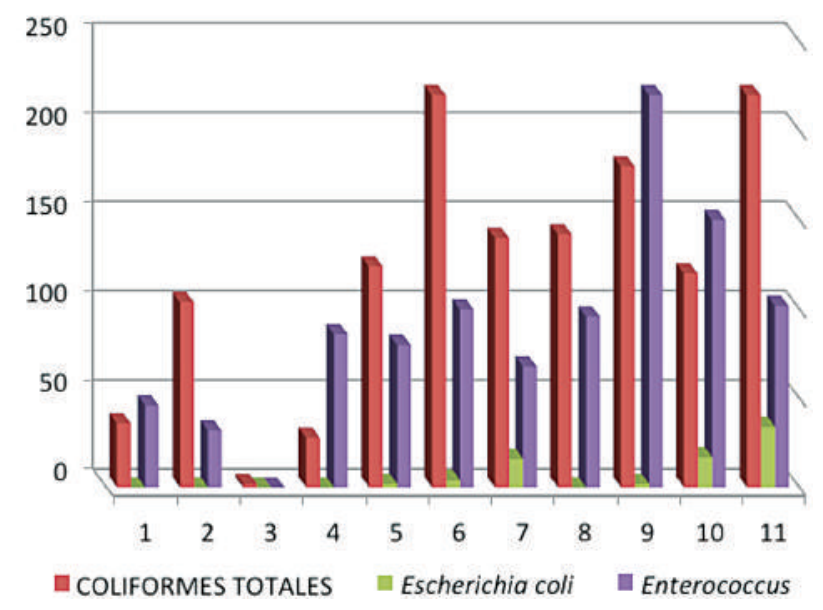

Figura 3. Promedio de los recuentos en Unidades Formadoras de Colonia / 100mL durante las dos épocas de muestreo

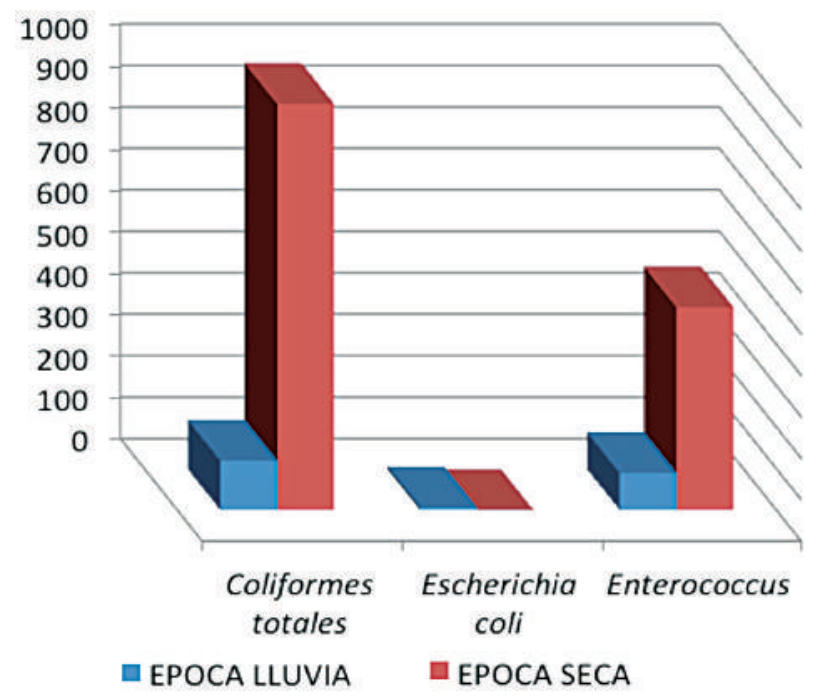

\section{Enterococcus}

Los recuentos de este género bacteriano son mucho más bajos en época de lluvia con un rango entre 0 y $220 \mathrm{UFC} / 100 \mathrm{~mL}$ (Tabla 3, Figura 4), en comparación con la época seca que se aumentan desde 240 hasta incontables UFC/100mL (Tabla 2, Figura 3). Para la época de lluvias el promedio es de $90 \mathrm{UFC} / 100 \mathrm{~mL}$ y para la época seca el promedio es de $490 \mathrm{UFC} / 100 \mathrm{~mL}$ (Figura 5).

Tabla 2. Recuento en Unidades Formadoras de Colonia /100mL en época seca

\begin{tabular}{|llll|}
$\begin{array}{c}\text { Sitio } \\
\text { de análisis }\end{array}$ & $\begin{array}{c}\text { Coliformes } \\
\text { totales }\end{array}$ & $\begin{array}{c}\text { Escherichia } \\
\text { coli }\end{array}$ & Enterococcus \\
\hline 1 & 1200 & 0 & 258 \\
\hline 2 & 1200 & 0 & 450 \\
\hline 3 & 1080 & 0 & 240 \\
\hline 4 & 1200 & 0 & 460 \\
\hline 5 & 1200 & 0 & 494 \\
\hline 6 & 1200 & 0 & 640 \\
\hline 7 & 1200 & 0 & 774 \\
\hline 8 & 80 & 0 & 264 \\
\hline 9 & 1200 & 0 & 1200 \\
\hline 10 & 0 & 0 & 340 \\
\hline 11 & 1200 & 0 & 246 \\
\hline
\end{tabular}

Tabla 3. Recuento en Unidades Formadoras de Colonia /100mL en época lluvia

\begin{tabular}{|llll|}
$\begin{array}{c}\text { Sitio } \\
\text { de análisis }\end{array}$ & $\begin{array}{c}\text { Coliformes } \\
\text { totales }\end{array}$ & $\begin{array}{c}\text { Escherichia } \\
\text { coli }\end{array}$ & Enterococcus \\
\hline 1 & 36 & 0 & 46 \\
\hline 2 & 104 & 0 & 32 \\
\hline 3 & 2 & 0 & 0 \\
\hline 4 & 28 & 0 & 86 \\
\hline 5 & 124 & 2 & 80 \\
\hline 6 & 220 & 4 & 100 \\
\hline 7 & 140 & 16 & 68 \\
\hline 8 & 142 & 0 & 96 \\
\hline 9 & 180 & 2 & 220 \\
\hline 10 & 120 & 17 & 150 \\
\hline 11 & 220 & 34 & 102 \\
\hline
\end{tabular}




\section{Discusión}

La presencia de coliformes totales indica que la contaminación es reciente $(8,9)$. En este estudio, en época de lluvia, nueve de los once puntos, presentaron recuentos de coliformes totales bajos, esto se puede explicar porque con las lluvias aumentan el nivel de los afluentes y por ende su escorrentía, lo que permite el arrastre de las capas superficiales y todo lo que existe en ellas (10). Estas aguas, según el Decreto 1594/84 pueden destinarse para potabilización, agricultura y fines recreativos (11). Por el contrario, dos puntos presentaron recuentos elevados, el punto 6 y el punto 11; el agua de estos puntos no puede ser destinada para ninguno de los fines descritos en el decreto anteriormente nombrado (11).

Ávila y Estupiñán, en el estudio realizado en el agua de los humedales Arcial, El Porro, Cintura, Bañó, Pantano Bonito y Charco Pescado, reportaron resultados opuestos con recuentos altos en época de lluvia entre 20000 y 120000 UFC/100mL debido a la entrada de agua contaminada de otras fuentes de agua como caños y ríos (12). Estas fuentes de agua se localizan en la costa norte del país donde las condiciones geográficas y climáticas son distintas. En otro estudio realizado por Cámbara y colaboradores (2010) en la subcuenca del río Quiscab, se encontraron altas concentraciones de coliformes totales y coliformes fecales en época de lluvia, razón por la cual determinaron que esta agua no es apta para consumo humano (13). Ramos y colaboradores (2008) en sus análisis en la Bahía de Santa Marta, encontraron que en época de mayores precipitaciones se elevaba el número de coliformes totales y coliformes fecales como consecuencia de la contaminación por emisarios submarinos, natación y buceo, entre otras (14).

Durante la época seca se presentaron altos recuentos de coliformes totales en la mayoría de las muestras, como consecuencia de la gran afluencia de turistas que visitan el parque en esta temporada. Sin embargo en las aguas de los puntos 8 y 10 los recuentos fueron bajos. El hecho de encontrar estas bacterias en época seca, coincide con estudios realizados en aguas obtenidas de un área silvestre en Escocia, por McDonald y colaboradores (2008), quienes reportan que la presencia de estos indicadores fue más alta en época de verano, en donde más del $85 \%$ de las muestras presentaban coliformes totales sobre todo en los sitios frecuentados por visitantes y zonas de camping (15).

Otro de los microorganismos evaluados fue la Escherichia coli, que mostró recuentos entre 0 y 34 $\mathrm{UFC} / 100 \mathrm{~mL}$ en las muestras analizadas durante la época de lluvia. Las muestras 1,10 y 11 presentaron recuentos altos debido a la interacción frecuente con el hombre y los animales. La presencia de Escherichia coli en las muestras 5, 6 y 7 puede ser consecuencia de la formación de biopelículas en el sistema de distribución; tal como lo afirman Knobelsdorf y Mujeriego (1997) que señalan que el crecimiento bacteriano en los sistemas de distribución del agua genera un deterioro en la calidad de la misma, debido a que el flujo de agua de estos sistemas favorece el transporte de bacterias y nutrientes que se adhieren a las paredes de las tuberías y forman películas bacterianas en estas superficies (16).

A su vez Sousa et al., proponen que es importante realizar mantenimientos en los sistemas de distribución para controlar así la formación de biofilm que alteren la calidad del agua (17). La presencia de Escherichia coli en el agua señala contaminación reciente de origen fecal; esta bacteria representa un riesgo para la salud. En los demás puntos no se aisló Escherichia coli debido a que esta requiere condiciones apropiadas para recuperarse del estrés fisiológico al que se encuentra sometida en el ambiente acuático; demostrado esto, en los estudios de Hazent et al., que sugieren que la Escherichia coli es un indicador fecal poco eficiente para la evaluación de la calidad en aguas tropicales (19).

En un estudio realizado por Asli Kacar (20062007), en cinco ríos de Turquía se obtuvieron recuentos altos de coliformes fecales en época de 
lluvia, posiblemente causados por contaminación de aguas residuales domésticas y heces de animales (20). En la ciénaga Mata de Palma Ávila y Estupiñán durante su investigación, hallaron elevados recuentos entre 160000 y 3220000 de UFC/100mL de Escherichia coli durante la época de lluvia de junio de 2007 y determinaron que esta agua no puede ser utilizada para uso recreativo y agrícola (21).

Algunos puntos durante la época seca mostraron recuentos entre 1 y $11 \mathrm{UFC} / 100 \mathrm{~mL}$ de Escherichia coli por lo que esta agua no puede ser usada para potabilización ni consumo humano (Decreto 1594/84; Resolución 2115 de 2007) (11,22). El hecho de que no se hayan encontrado relevantes recuentos de Escherichia coli en época seca aun cuando se obtuvieron recuentos de coliformes totales altos, puede explicarse porque la Escherichia coli posee menor resistencia a las condiciones ambientales del agua lo que hace que su aislamiento, en cada una de las muestras, sea más difícil $(18,23)$.

En cuanto al género Enterococcus se presentaron recuentos entre 0 a $220 \mathrm{UFC} / 100 \mathrm{~mL}$ en época de lluvias, por el contrario durante la época seca los recuentos fueron elevados. En las diferentes muestras analizadas en esta investigación se encontró un alto número de Enterococcus en época seca con respecto a la época de lluvia, lo que seńala que este indicador presenta mayor resistencia a factores de estrés ambiental como $\mathrm{pH}$ y temperatura $\left(10\right.$ y $\left.60^{\circ} \mathrm{C}\right)$ en comparación con la Escherichia coli $(24,25)$.

La presencia de Enterococcus en aguas está asociada a contaminación fecal de origen tanto humano como animal. Si se tiene en cuenta la relación de Escherichia coli/ Enterococcus faecalis propuesta por Fernández y Molina et al (24) podemos concluir que la fuente posible de contaminación durante la época seca, en las muestras del Parque Chicaque, fueron de origen animal, esto podría explicarse porque el agua durante su recorrido presenta una alta probabilidad de contaminación por la presencia de animales silvestres que actúan como portadores de patógenos. Anteriormente se ha descrito demostrado que la presencia de aves y otros animales silvestres está relacionada con la alteración de la calidad bacteriológica del agua (25).

La presencia de estos tres indicadores evaluados en el agua se relaciona con la existencia de microorganismos patógenos como: Campylobacter jejunii, Salmonella spp, Legionella, Escherichia coli enteropatogénica, Klebsiella spp. entre otros; causantes de enfermedades hídricas como el síndrome urémico, bacteremias, intoxicaciones alimentarias, diarreas, fiebre tifoidea, fiebre paratifoidea, meningitis neonatal, infecciones urinarias, oftálmicas y de piel entre otras $(8,18,20,24,26-28)$.

\section{Agradecimientos}

Agradecemos especialmente a las estudiantes del Programa de Bacteriología y Laboratorio Clínico de la Universidad Colegio Mayor de Cundinamarca: Saldaña Chaves Diana Carolina, Troncoso González Andrea Del Pilar. A David Escobar por su apoyo y colaboración durante la toma de muestras en el Parque Natural Chicaque.

\section{Referencias}

1. Delgado Gómez Y, Miravet Regalado ME, Núñez Graell R. Indicadores microbiológicos de la calidad del agua en la costa oeste de la ciudad de la Habana. Higiene y Sanidad Ambiental. 2008. 8:387-39.

2. Arcos Pulido MP, Ávila de Navia SL, Estupiñán Torres SM, Gómez Prieto AC. Indicadores Microbiológicos de las fuentes de agua. Revista NOVA. 2005. 3:69-78.

3. Página web Parque Natural Chicaque. www.chicaque.com. Consultada Enero de 2013

4. Comunicación Personal. Dr. David Escobar. Subgerente Parque Natural Chicaque. 2013

5. World Health Organization. Guidelines for Drinking-water Quality. Second edition. Ginebra: OMS; 1993 (en línea), (Revisado el 20 de noviembre de 2012); Disponible en: http://www.who.int/water_sanitation_health/dwq/guidelines/ es/index.html.

6. ICONTEC. Norma Técnica Colombiana 813, Normas oficiales para la calidad del agua en Colombia. Bogotá, ICONTEC (en línea) (Revisado el 15 de Marzo de 2012). Disponible en: http://poseidon.unalmed.edu.co/PGA/materias/funda_cont/ docs/normas/agua_potable/colombia.

7. Arcos, M., Avila, S., Estupiñán, M., Gómez, A. Indicadores microbiológicos de contaminación de las fuentes de agua. NOVA. 2005. Vol. 3: 69-76. 
8. Colombia, Ministerio de la Protección Social. Decreto 1575 de 2007, por el cual se establece el Sistema para la Protección y Control de la Calidad del Agua para Consumo Humano. Bogotá: Ministerio; 2007.

9. Urzúa F. Determinación de la eficacia de la planta de tratamiento de agua residual de estanzuela, zacapa. (Tesis pre grado). Guatemala; 2008

10. Colombia, Ministerio de Protección Social y Ministerio de Agricultura. Decreto 1594 de 1984, Por el cual se reglamenta parcialmente el Título I de la Ley 09 de 1979, así como el Capítulo II del Título VI - Parte III - Libro II y el Título III de la Parte III Libro I del Decreto 2811 de 1974 en cuanto a usos del agua y residuos líquidos. Bogotá D.C; 1984.

11. Ávila de Navia SL, Estupiñán Torres SM. Evaluación de la calidad microbiológica del agua de los humedales Arcial, el Porro y Cintura (río San Jorge), y los humedales Baño, Pantano Bonito y Charco Pescado (río Sinú) en Colombia Diversidad Biótica IX 2010.

12. Padilla C, García N, Pérez W. Caracterización físico-química y bacteriológica, en dos épocas del año, de la subcuenca del río Quiscab, Guatemala.Revista Ciencias Técnicas Agropecuarias. 2010. 19(3): 43-46.

13. Ramos L,Vidal L, Vilardy S, Saavedra L. Análisis de la contaminación microbiológica(coliformes totales y fecales) en la Bahía de Santa Marta, Caribe colombiano.Acta biol. Colomb. 2008. 13 (3): $87-98$

14. McDonald A.T,Chapman P.J, Fukasawa K. The microbial status of natural waters in a protected wilderness area. Journal of Environmental Management. 2008. 87: 600-608.

15. Knobelsdorf J, Mujeriego R. Crecimiento bacteriano en las redes de distribución de agua potable una revisión bibliográfica. Revista de ingeniería del agua. 1997. 4 (2):17-18.

16. Sousa C, Colmenares M \& Correia A. Contaminación bacteriológica en los sistema. Boletín de malariología y salud ambiental vol. XLVIII, No 1, Enero-Julio, 2008.

17. 1Ávila de Navia SL, Estupiñan Torres SM. Calidad sanitaria del agua de la Ciénaga Mata de Palma en el Departamento del Cesar, Colombia. Revista NOVA. 2009. 7(1): 85-90.

18. Mercado Santiago and Hazent Terry. Comparison of Four Membrane Filter Methods for Fecal Coliform Enumeration in Tropical Waters. Applied and Environmental Microbiology. 1987. 2922-2928.
19. Asli Kacar. Analysis of spatial and temporal variation in the levels of microbial fecal. Ecological Indicators. 2011. 11:1360-1365.

20. Colombia, Ministerio de Protección Social y Ministerio de Agricultura. Decreto 1594 de 1984, Por el cual se reglamenta parcialmente el Título I de la Ley 09 de 1979, así como el Capítulo II del Título VI - Parte III - Libro II y el Título III de la Parte III Libro I del Decreto 2811 de 1974 en cuanto a usos del agua y residuos líquidos. Bogotá D.C; 1984.

21. Ministerio de la Protección Social, Ministerio de Ambiente, Vivienda y Desarrollo Territorial. Resolución 2115, Junio 2007, por medio de la cual se señalan características, instrumentos básicos y frecuencias del sistema de control y vigilancia para la calidad del agua para consumo humano. Bogotá: el Ministerio; (en línea) 2007 (fecha de acceso 5 de febrero de 2012). Disponible en: http://www.minproteccionsocial.gov. $\mathrm{co} / \mathrm{VBeContent} / \mathrm{News}$ Detail.asp? ID =16364\&IDCompany=3

22. Organización mundial de la salud. Guías para la calidad del agua potable, tercera edición. (En línea) (Revisado: 15-072012). Disponible en: http://www.who.int/water_sanitation health/dwq/gdwq3rev/es/index.html

23. Fernández - Molina M. C., A. Alvarez - Alcántara y M. A. Espigares - García. Transmisión fecohídrica y virus de la hepatitis A. Higiene y Sanidad Ambiental. 2001. 1: 8-24.

24. Namihira P, Barrera G, Márquez A. 2012. Contaminación por bacterias fecales en el Lago Huayamilpas, México. D.F. Revista Hidrobiológica. 12: 129-136.

25. Azizullah A, Muhammad Nasir Khan Khattak, Peter Richter, Donat-Peter Häder. Water pollution in Pakistan and its impact on public health. Environment International. 2011. 37:479-497.

26. Schaffter N, Parriaux A. Pathogenic-bacterial water contamination in mountainous catchments. Water Research. 2002. 36: 131-139.

27. Cabral João P. S. Water Microbiology. Bacterial Pathogens and Water. International Journal of Environmental Research and Public Health. 2010. 7: 3657-3703.

28. Environment Agency. 2002. Standing Committee of Analysts, The Microbiology of Drinking Water - Part 1 - Water Quality and Public Health, Methods for the Examination of Waters and Associated Materials. Environment Agency. United States. 2002. 